\title{
Female Adolescent Physical Activity Motivation: A Qualitative Implementation of the BRSQ
}

\author{
Sinead Nelson, Jimmy Smith* \\ Assistant Professor, Department of Sport and Physical Education, School of Education, Gonzaga University, \\ USA
}

*Corresponding Author: Jimmy Smith, Assistant Professor, Department of Sport and Physical Education, School of Education, Gonzaga University, USA

\begin{abstract}
Youth sport participation rates are at an all-time high, but one segment of the youth population showing notable declines is female adolescents. Research indicates that time spent on physical activity shows decline in traditional United States high school ages 14 through 18. The current research studied 37 female adolescent student athletes' individual motivation, to understand the factors that motivate female high school student athletes to continue sport participation beyond freshman year. Through this knowledge, the current research aimed to counter the trend of declining female athletic participation in the high school years. Study results indicated that female adolescents are most impacted by positive team cohesion, developing values that impact life outside of athletics, and playing for themselves rather than to satisfy others (i.e. parents, teammates, coaches and peers). These results regarding motivational factors will allow coaches and administrators to develop effective programs to increase female participation in sport.
\end{abstract}

Keywords: High School, Adolescent, Motivation, BRSQ, Self-Determination Theory

\section{INTRODUCTION}

Research has shown a distinct decline in recreational activities and sport participation of youth during the mid-adolescent years. Analyzing data from the National Health Interview survey, results showed that rates of physical activity among adolescents declined the most between ages 15 and 18, the traditional ages of United States high school sophomores, juniors and seniors. A significant difference of these results was between male and female adolescent physical activity at age 17 (Caspersen, Pereira, \& Curran, 2000). Rates of leisure time physical inactivity increased from $6 \%$ at age 14 to nearly $24 \%$ by age 20 . These findings were consistently corroborated over the last two decades, showing decline in physical activity during the adolescent years, especially among females (Kin-Isler, Asci, Altintas, \& Guven-Karaban, 2009; Orhan, 2015).

While trends in physical activity among adolescents are well documented through both primary and secondary research (c.f.; Aaron, Storti, Robertson, Kriska, \& Laporte, 2002; Allison \& Adlaf, 1997; Berger, O’Reilly, Parent, Séguin, \& Hernandez, 2008; Finne, Bucksch, Lampert, \& Kolip, 2011), analysis of individual motivation behind such activity is far less developed, especially within the United States. Most motivation-focused physical activity studies conducted in the last decade occurred outside of the U.S., with differences in overall culture, sport choices and athletic climates (Allen, 2003; Dwyer, Allison, Goldenberg, Fein, Yoshida, \& Boutilier, 2006; Escartí \& Gutiérrez, 2001; Stubbe, Boomsma, \& de Geus, 2005; Whitehead \& Biddle, 2008). Replication of these studies are limited within the United States, nor have they focused sufficiently on adolescent females in a qualitative methods manner. A qualitative approach to the topic allows for richer descriptions, adding a value to the results unattainable through quantitative methods.

Previous studies have demonstrated the significant decline of overall adolescent physical activity highlighted among mid-adolescent females, and additional research has developed a range of potential intrinsic, extrinsic and a motivational impacts. To date, there has been limited research that has found correlations between the two areas of study. To bridge this gap, the current research utilized a case study format, grounded on Lonsdale, Hodge and Rose's (2008) model of motivational theory, to understand what high school females seek out in physical activities in the western region of the 
United States. Lonsdale et al.'s model separates individual motivation into nine dimensions encompassing a motivation, intrinsic motivation, and extrinsic motivation. The current study results contributes to the existing body of knowledge on adolescent motivation by focusing on a demographic not frequently highlighted in the current literature, and in turn allow for development of programs and leagues adapted to their needs and desires. Therefore, the research question became: What motivates adolescent females to continue participating in high school athletics beyond their first year in high school?

\subsection{Literature Review}

Pre-2000 studies of adolescent sport participation and its relative decline focused on impacts of gender (Garcia, Broda, Frenn, Coviak, Pender, \& Ronis, 1995), age (Garcia et al., 1995), demographic placement (Telama \& Yang, 2000), and activity selection (Aaron et al., 2002). Shortly after the turn of the century, research shifted focus towards analysis of adolescents' motivation to be physically active (Allen, 2003; Berger et al., 2008), perceived physical activity barriers and constraints (Casper, Bocarro, Kanters, \& Floyd, 2011; Dwyer et al., 2006), overall perceptions of physical activity (Whitehead \& Biddle, 2008), and demographic correlations (Finne et al., 2011). Early research approached the concept of adolescent physical activity decline from a range of impacts and sources. In a review of 54 studies conducted between 1970 and 1998 related to child and adolescent physical activity and fitness, Sallis, Prochaska and Taylor (2000) concluded that "males are about 15 to $25 \%$ more active than females and that, during the school-age years, activity levels decline at a rate of about $2.7 \%$ per year in males and $7.4 \%$ per year in females" (p. 407).

While Sallis et al's study utilized a collection of existing data to understand research trends, Telama and Yang (2000) conducted an empirical study to analyze physical activity variables among adolescents. A questionnaire was used to measure physical activity, with questions about "frequency and intensity of leisure-time physical activity, participation in sport club training, participation in sport competitions, and the respondents' habitual ways of spending their leisure time" (p. 1618). The data was collected in three-year increments over a nine-year period, and all study participants showed decline in physical activity, with the sharpest drop occurring between age 12 and 15 for males and between age 15 and 18 for females (Telama \& Yang, 2000). Throughout the study, females reported consistently lower rates of physical activity.

The findings of Telama and Yang (2000) were corroborated by Berger et al (2008) in their analysis of sport participation among Canadian adolescents. Berger et al's findings also showed overall decline in sport participation between ages 15 and 19, with females again having a lower overall sport participation rate than males. A report from the Women's Sports Foundation (2008) yielded similar results, as well as highlighted that girls started sports later than boys, dropped out sooner, and had a higher quantity of drop outs. Between junior high and high school, females classified as highly involved athletes dropped from $23 \%$ to $14 \%$, while rates of non-athletes rose from $28 \%$ to $34 \%$ (Sabo \& Veliz, 2008). Most recently, results from the Always Confidence \& Puberty Survey indicated that by age 17, more than half of girls quit sports altogether (MSLGROUP Research, 2016). The literature's findings of the sharpest decline for physical activity and sport participation occurring in adolescence, combined with consistently less physical activity for females, led the current research to focus primarily on the adolescent female demographic.

\subsection{Gender Correlation}

Existing literature established the age range of significant decline in physical activity, and also revealed notable differences between genders. Aaron et al (2002) concluded a four-year study with significant mid-adolescent physical activity decline results, aligned with the age-related findings of Telama and Yang (2000). Aaron et al's study used the Modifiable Activity Questionnaire for Adolescents to measure leisure time and competitive activity participation over the four-year period. Each spring, participants completed a questionnaire indicating which activities they had participated during the previous year and estimated how many hours were spent on each activity. Aaron et al (2002) concluded that "the probability of maintaining participation in a specific activity during the 4 years was...0.02 to 0.47 for female adolescents and 0.04 to 0.71 for male adolescents" (p. 1075). These statistics indicated that male adolescents were nearly twice as likely as female adolescents to participate in the same physical activity for four consecutive years. Similar to Telama and Yang's (2000) findings, Aaron et al's results also indicated consistently less physical activity participation for 
females. The current research elected to focus on female adolescents because of the well-established age range of maximum physical activity decline, consistently lower rates of participation for females, and Sallis et al's indication of notably less empirical research focused on females.

\section{THEORETICAL FRAMEWORK}

Research approaching the turn of the century examined the relationship between motivation and selfesteem (Whitehead, Corbin, \& Fox, 1997), in addition to achievement values and personal motivation (Graham, 1997), and correlation concerning motivation, culture, and gender (Weinberg et al., 2000). All three studies indicated that motivation does not singularly develop, but rather that demographic, psychographic and social interactions all impact an individual's motivation. Around the turn of the century, however, Ryan and Deci's (2000) self-determination theory established that "human beings can be proactive and engaged or, alternatively, passive and alienated, largely as a function of the social conditions in which they develop and function" (Ryan \& Deci, 2000, p. 68). Following Ryan and Deci's (2000) development of self-determination theory, later research developed consistent positive correlations between environments supporting autonomy, competence and relatedness, and increased intrinsic and extrinsic motivation (Black \& Deci, 2000; Gagné \& Deci, 2005; Niemiec \& Ryan, 2009; Ryan, Rigby, \& Przbylski, 2006).

\subsection{Behavioral Regulation in Sport Questionnaire}

Developed in 2008, Lonsdale's Behavioral Regulation in Sports Questionnaire (BRSQ) utilizes a nine-dimensional motivational model to "test a new measure of competitive sport participants' intrinsic motivation, extrinsic motivation, and amotivation" (p. 323). The model is based on Ryan \& Deci's self-determination theory, as seen in Table 1 , and separates motivation into three main categories: intrinsic, extrinsic, and amotivation. The current research was grounded in Lonsdale et al.'s model due to its foundation in self-determination motivation theory and direct focus on sport and athletics.

Table1. BRSQ Factors of motivation

\begin{tabular}{|l|l|}
\hline Intrinsic Motivation & $\begin{array}{l}\text { 1. General intrinsic motivation } \\
\text { 2. Intrinsic motivation to know } \\
\text { 3. Intrinsic motivation toward accomplishments } \\
\text { 4. Intrinsic motivation to experience stimulation }\end{array}$ \\
\hline Extrinsic Motivation & $\begin{array}{l}\text { 1. Integrated regulation: personally endorsed needs, values and goals } \\
\text { 2. Identified regulation: acceptance of reasons to do something } \\
\text { independent of personal enjoyment } \\
\text { 3. Introjected regulation: desire to avoid guilt or shame } \\
\text { 4. External regulation: desire to gain praise or avoid punishment from others }\end{array}$ \\
\hline Amotivation & $\begin{array}{l}\text { 1. Lack of motivation, lack of intention to participate, and feelings of "going } \\
\text { through the motions." }\end{array}$ \\
\hline
\end{tabular}

To verify the validity of the BRSQ, scores from Lonsdale et al's questionnaire were compared to scores from two versions of the Sport Motivation Scale (c.f., Mallett, Kawabata, Newcombe, OteroForere, \& Jackson, 2007; Pelletier et al., 1995). The comparison's results indicated "equal or superior reliability and factorial validity" (Lonsdale et al., 2008, p. 323) by the BRSQ.

\section{METHODS}

As aforementioned, notable gaps exist in motivational research studies related to physical activity of adolescent females, specifically in sample populations, geographic region of studies, and methods of data collection. The current research attempted to begin to bridge these gaps by conducting an empirical qualitative study focused on high school female student-athletes. Using an exploratory case study format to understand the situation, an interpretive knowledge base catered to collecting a wide range of potential results (Yin, 2009). The data collected was too complex to reduce to numbers, so an interpretivist base allowed for data analysis "using words, statements and other non-numerical measures, collecting data from the viewpoint of the participant" (Jones, 2015, p. 22).

\subsection{Population and Sample}

The population for the current case study was adolescent female student athletes from two high schools within the same school district in the Far West- region of the United States in their sophomore, junior, or senior years. Schools were selected for their close proximity to the researcher 
and voluntary interest in participating. Case study participants were selected using a convenience sampling technique (Jones, 2015) from the given population of female student athletes, limited to athletes actively participating in a given sport, who participated in the same sport the previous year. Following approval by each high school's principal, athletic director and involved head coaches, students within the desired population had the opportunity to voluntarily participate in the study with informed consent from a parent or legal guardian.

\subsection{Data Collection}

Data was collected through semi-structured individual interviews with participants, using questions derived from the BRSQ (Lonsdale et al., 2008). The start of discussions with participants attempted to establish rapport with the student athletes, by discussing their background and athletic history. The interview then progressed into questions focused specifically on sport motivation. Each student athlete was presented with 27 statements on $3 \times 5$ index cards, where each statement reflected one of Lonsdale et al's nine factors of motivation in an age-appropriate manner. The cards were utilized to present Lonsdale's BRSQ-type questions to adolescents in a conversational manner rather than, for example, generating conversation through reading of definitions based on Lonsdale et al. The index cards created a standardized process to the conversation with high school student-athletes. This was similar to that of Harry, Sturges, and Klingner's (2005) use of index cards with special education teachers to determine themes regarding placement of students into certain special education programs and whether or not teachers agreed with themes, disagreed with themes, or thought the themes were irrelevant to the situation. The index cards for this research catered to both visual and kinesthetic learners, afforded the student athletes the flexibility to move the cards and arrange the cards comfortably, and gave them something to occupy their hands. Student athletes were asked to reflect on statements that they found most accurate to their individual motivation, least accurate to their individual motivation, and most accurate to their perception of their teammates' motivations.

The semi-structured interview allowed participants to self-report motivational factors from least important to most important in addition to having the freedom to discuss additional relevant details. Interview audio was recorded and transcribed. To protect the identity of participants, nonessential identifiers were removed during transcription.

\subsection{Data Analysis}

The collected data was analyzed inductively using "a data-driven process of coding the data without trying to fit it into a pre-existing coding frame" (Braun \& Clarke, 2006, p. 89). Themes were developed through counting at a semantic level, noting whether a given concept was discussed in each participant's interview. Results were categorized by most frequently referenced themes, and analyzed in comparison to Lonsdale's model. Analysis developed themes from frequently referenced topics, the most common positive motivations, and the most frequently dismissed motivations.

\section{RESUlts}

Interviews were conducted individually with 37 participants from two high schools in the Far West region of the United States. A breakdown of the participants' grade levels, sports and competition levels can be found in Table 2 .

Table2. Demographics of study participants

\begin{tabular}{|l|l|}
\hline \multicolumn{1}{|c|}{ Grade } & \multicolumn{1}{c|}{ Participants } \\
\hline Sophomore & 17 \\
\hline Junior & 7 \\
\hline Senior & 13 \\
\hline Sport & \\
\hline Soccer & 15 \\
\hline Volleyball & 13 \\
\hline Basketball & 5 \\
\hline Level & 4 \\
\hline Varsity & \\
\hline Junior Varsity & 30 \\
\hline
\end{tabular}

On average, students chose 4.2 cards for statements most accurate to their motivation, 3.2 for least 
accurate statements, and 3.1 that reflected their perception of their teammates' motivation. The most prominent themes were the impacts of team cohesion, sport values carrying over to life outside of athletics, playing for oneself, and awareness of future athletic prospects. A breakdown of each motivational factor can be found in Table 3, organized by the frequency of responses for each category of motivation as most impactful, (+) and least impactful (-) on each student-athlete's motivation.

Table3. Participant responses to each factor of motivation, completing the sentence 'I participate in my sport...'

\begin{tabular}{|c|c|c|}
\hline & + & - \\
\hline \multicolumn{3}{|l|}{$\begin{array}{l}\text { Intrinsic motivation - General } \\
\end{array}$} \\
\hline ...because it's an enjoyable way to spend my time. & 9 & 1 \\
\hline ...because it's fun. & 8 & 1 \\
\hline ...because I like it. & 6 & 0 \\
\hline Total & 23 & 2 \\
\hline \multicolumn{3}{|l|}{ Intrinsic motivation - Knowledge } \\
\hline ...because I enjoy learning new techniques. & 0 & 1 \\
\hline ...because I enjoy learning something new about my sport. & 0 & 1 \\
\hline ...because I like figuring out new strategies. & 1 & 3 \\
\hline Total & 1 & 5 \\
\hline \multicolumn{3}{|l|}{ Intrinsic motivation - Stimulation } \\
\hline ...because I like doing things that are exciting. & 3 & 1 \\
\hline ...because I like the feeling of being totally immersed in an activity & 3 & 2 \\
\hline ...because of the positive feelings that I experience while playing. & 13 & 1 \\
\hline Total & 19 & 4 \\
\hline \multicolumn{3}{|l|}{ Intrinsic motivation - Achievement } \\
\hline ...because I feel personal satisfaction while mastering difficult skills & 4 & 1 \\
\hline ...because I enjoy the sense of achievement I get from improving my weaknesses. & 11 & 1 \\
\hline ...because I get a sense of accomplishment from working toward something important. & 9 & 0 \\
\hline Total & 24 & 2 \\
\hline \multicolumn{3}{|l|}{ Extrinsic motivation - Integrated regulation } \\
\hline ...because it's an opportunity to just be who I am. & 5 & 3 \\
\hline ...because being an athlete is an important part of who I am. & 10 & 0 \\
\hline ...because it is meaningful to my personal values. & 7 & 0 \\
\hline Total & 22 & 3 \\
\hline $\begin{array}{l}\text { Extrinsic motivation - Identified regulation } \\
\end{array}$ & 31 & 4 \\
\hline ...because it is one of the best ways to meet people and maintain good relationships. & 17 & 3 \\
\hline ...because it teaches me self-discipline. & 6 & 0 \\
\hline ...because it helps me develop life skills. & 8 & 1 \\
\hline Total & 31 & 4 \\
\hline \multicolumn{3}{|l|}{ Extrinsic motivation - Introjected regulation } \\
\hline ...because I feel like I have to. & 2 & 18 \\
\hline ...because it is necessary to do sports to stay in shape. & 15 & 3 \\
\hline ...because I would feel like a failure if I quit. & 6 & 10 \\
\hline Total & 23 & 31 \\
\hline \multicolumn{3}{|l|}{ Extrinsic motivation - External regulation } \\
\hline ...for the prestige of being an athlete. & 3 & 6 \\
\hline ...to impress other people, like family, friends, teammates, rivals, or coaches. & 6 & 16 \\
\hline ...because if I don't, other people could be disappointed with me. & 2 & 13 \\
\hline Total & 11 & 35 \\
\hline \multicolumn{3}{|l|}{ Amotivation } \\
\hline ...but I'm not sure why. & 0 & 10 \\
\hline I used to have good reasons for doing sports but now I don't really know. & 1 & 4 \\
\hline ...but I don’t really think my place is in sports. & 0 & 14 \\
\hline Total & 1 & 28 \\
\hline
\end{tabular}

\subsection{Team Cohesion}

The most prevalent theme (team cohesion) appeared in $59.5 \%(\mathrm{n}=22)$ of participants' interviews, the impact of team cohesion on motivation to continue participating. It was named as a top factor impacting motivation by $45.9 \%$ of participants $(n=17)$. While not always expressed specifically as a primary reason for joining sports, participants frequently discussed that strong team dynamic notably 
strengthened motivation throughout the sport season, and aided in choosing to return to the same sport or team the following year.

I met a lot of new people and they were super supportive, really great people. We felt like a family, so I continued participating in my sport this year and continued to meet new people and talk to new people (Interview 12).

I struggled freshman year of high school. I had depression and anxiety...It was really rough for me, and it was brought up this year too, but soccer was the one escape that I had. I could literally talk to (my teammates) about anything. When I'm trying to convince people to play soccer, I'm like How can you not? I see what you're struggling with, just come play. In that way, absolutely if I didn't have my soccer team I would go crazy (Interview 37).

\subsection{Values Transcending Athletics}

The second frequently referenced theme was the values learned in sport impacting life beyond athletics, as discussed by $56.7 \%(\mathrm{n}=21)$ of participants. The BRSQ categorized developing life skills, learning self-discipline, and maintaining good relationships as identified regulation, all of which were reflected in the two most prominent themes. Results showed $40.5 \%(\mathrm{n}=15)$ of participants selected at least one identified regulation statement as a highly impacting factor of motivation, while only $8.1 \%$ $(n=3)$ selected one as a least impactful factor.

On the court you have to be controlled and hold your emotions sometimes, and in life you have to do the same thing. You can't freak out if something happens. You have to figure out what to do about it (Interview 25).

As a high school athlete, you have to balance and work on not procrastinating on either sports or school. I have to communicate a lot to my teachers and to my coaches with schoolwork and volleyball, both ways. It's a lot of life skills. Sports taught me more than just to be athletic (Interview 1).

\subsection{Playing for Oneself}

There were twelve statement cards that reflected a factor of intrinsic motivation; $83.8 \%(n=31)$ of participants chose at least one intrinsic as a positive motivational factor. Furthermore, $40.1 \%(\mathrm{n}=15)$ of participants explicitly discussed the importance of playing for oneself, as opposed to playing to please others (i.e. parents, coaches, teammates, or peers). The BRSQ also defines the opposite motivation to gain praise or avoid punishment from others - as external regulation, which $64.8 \%$ of student athletes $(n=24)$ selected as a least impactful factor on their personal motivation. $24.3 \%(n=9)$ chose multiple external regulation statements as least relevant to their motivation.

I do it for myself...because it makes me feel good about myself. I don't really mind what other people think about me or the way I play (Interview 29).

I only do it for myself. I always want to take extra steps to become better and that's just for me, not for anybody else or because I feel like I have to (Interview 11).

\subsection{Awareness of Future Prospects}

The final theme was a conscious awareness by student athletes on the potential of playing their respective sport in college, discussed by $43.2 \%(\mathrm{n}=16)$ of participants. Student athletes had mixed feelings about their college prospects: $37.5 \%$ of student athletes $(n=6)$ who addressed it did so with neutral or negative implications, while $62.5 \%$ of participants $(n=10)$ discussed it with positive impacts on their current motivation:

I'm not playing volleyball in college so I think I should stop wasting my time (Interview 17).

When you're younger you just think about it as fun, not thinking about college yet. But now thinking about college, it's more important. It's like, am I going to play college ball? So, it's not as fun anymore because you have to take it more seriously (Interview 29).

When I think of college, I just want the satisfaction of knowing that I made it. I don't want to feel the regret that I could have played, when I'm not playing anymore (Interview 32).

More than half of the seniors interviewed, 53.8\% ( $\mathrm{n}=7)$, discussed future athletic prospects, along 
with $41.2 \%$ of sophomores $(n=7)$ and $14.3 \%$ of juniors $(n=1)$. There was no correlation between the participants' school, sport, or level of current competition and whether the student athlete discussed their prospects as a post-high school athlete.

\section{DISCUSSION}

The purpose of this study was to understand the motivation of current adolescent female studentathletes, to aid future development of high school athletic programs for females. Existing literature indicates the peak decline in female physical activity during the mid-adolescent years, and although the declining rates of participation are well documented (Caspersen, Pereira, \& Curran, 2000; Aaron et al., 2002; Sabo \& Veliz, 2008; MSLGROUP Research, 2016), research to understand why that decline exists is underdeveloped. The guiding question for this study was: What motivates adolescent females to continue participating in high school athletics beyond their first year in high school?

The four prominent themes developed from the current research's results were the impacts of positive team cohesion, values learned in sport affecting life outside of sport, the importance of playing for oneself, and an awareness of post-high school athletic prospects. Due to the exploratory nature of the study (Yin, 2009), no hypotheses were drawn prior to conducting interviews. The research referenced in the literature review was primarily contextual. After completing the study and developing themes from the results, researchers pursued additional literature more specific to each individual theme.

\subsection{Team Cohesion}

Team cohesion has been studied, but not often correlated to high school female student athlete motivation. The current research found that a majority of study participants attributed increased motivation to return to high school athletics to a positive team dynamic, a result not frequently examined in other studies. Existing research focused largely on team coaches rather than the athletes. In one study focused on athlete leadership and team cohesion, Vincer and Loughead (2010) found that "individual perceptions of training and instruction, and social support positively influenced all four dimensions of cohesion" (p. 448). This correlates to the current research's findings, as social support was a consistently emerging sub-theme when student athletes discussed the value of positive team chemistry.

Research focusing on team cohesion and its impact on individual athletes is also limited; however, Paradis and Loughead (2012) conducted a quantitative study to examine team cohesion as a mediating factor between athlete leadership and satisfaction in youth sports. Results indicated that cohesion served as a mediator in youth sport between athlete leadership behaviors and satisfaction outcomes. Motivations related to overall enjoyment of sport were referenced 23 times by 20 different participants in the current research. Of the 20 student athletes that referenced fun, $65 \%(n=13)$ also discussed the value of positive team chemistry. Paradis and Loughead's (2012) findings align with the current research's results: relationships built through team cohesion can be strong enough to motivate student athletes to return to the same team. As expressed by interviewee 36,

Hanging out with each other and having that family and that bond, we're all family. That's why most of us stuck with our team, because we don't want to leave each other.

For some student athletes their respective teams can become like a second family, and those relationships can be strong enough factors to motivate the student athlete to continue playing. The direct correlation between positive team cohesion and increased individual motivation was a finding exclusive to the current research, and thus far the current population remains largely unexamined in the existing literature.

\subsection{Values Transcending Athletics}

A quantitative study conducted by Kromerova and Šukys (2016) on the correlation between adolescent involvement in sporting activities and internalization of moral values yielded some findings that aligned with the current research, and others that differed from the current research. They found that adolescent athletes had higher value internalization than non-athletes, but adolescents with higher sports experience showed lower internalization than those with less sports experience. The study was grounded in a similar theoretical framework to the current research, which facilitated a direct comparison between the impacting factors on moral internalization and on individual motivation. The female participants in both studies showed the highest rates of impact from identified 
regulation.

Similarities existed between Kromerova and Šukys' (2016) findings and the current research, but a notable distinction came from the source of moral development. Athlete participants in Kromerova and Šukys' research discussed how strongly they identified with a variety of value-related statements, but the values' development were not attributed to a specific experience. The current research contributes to the literature by drawing a direct connection between the participants' self-reported value in learning values through sport, developing those values into daily life, and returning to sport in order to continue developing both existing and new values. Existing research has emphasized the value of social development through sport (Kumar, 2017), the connection between sport values and parental influence (Kremer-Sadlik, \& Kim, 2007; Danioni, Barni, \& Rosnati, 2017), and the relation between manifested values and coach's character development competency (Stupuris, Šukys, \& Tilindienè, 2013). However, none pursued the source of the athlete's values, how any sport-sourced values have developed beyond athletics, or what impact learning values through sport has on athletes and their motivation.

\subsection{Playing for Oneself}

The theme of playing for oneself fundamentally came down to the conflict between intrinsic and extrinsic motivation, a concept well studied over the last six decades. Alderman and Wood (1976) found that the most important motivations among Canadian athletes aged 12-18 to participate in competitive sport were all extrinsic: status, prestige and recognition. Brodkin and Weiss (1990) studied competitive swimmers and found some distinctions between age groups: older children, high school and college-aged athletes highly valued social status, while pre-high school aged youth focused more on fun.

Two recent studies on athletic motivation suggest a shift towards intrinsic motivation, as found by Garcia-Mas et al (2010) in a study of competitive soccer players and by Pacheco, Mas, Olivárez and Avila (2012) among female collegiate student-athletes in Texas. Garcia-Mas et al (2010) found that "the intrinsic motivation is clearly predominant between the players" and "the intrinsic motivation shows higher correlations than the extrinsic motivation with the commitment of our players to sport" (p. 613-614). Pacheco et al (2012) had similar findings suggesting that most of their participants were motivated to play for reasons related to skill mastery, enjoyment, and ego, all of which are intrinsic motivators. Additionally, Pacheco et al's participants were not highly motivated by their parents or general affiliation and recognition.

In spite of differing populations, the results of both studies aligned with the current research, as intrinsic motivations were generally referenced as more positively impactful on motivation than extrinsic. Two of the six most commonly selected factors of motivation were related to mastery and achievement, and the two statements most frequently selected as not impactful on motivation related to feelings of obligation and desire for recognition.

\subsection{Awareness of Future Prospects}

Research regarding the pressure and impacts on high school athletes as they consider the potential to continue their athletic careers in college is largely unexplored. One previously studied connection between high school athletes and their awareness of future athletic prospects is in the concept of specialization, where athletes focus intense training on only one sport, and exclude all others (Jayanthi, Pinkham, Dugas, Patrick, \& Labella, 2013). In a study conducted by Buckley et al (2017) surveying 3090 high school, collegiate and professional athletes, $45.2 \%$ of high school athletes and $67.7 \%$ of collegiate athletes indicated that they had specialized to play a single sport in their adolescence. The age of specialization fell just over 14 years old, and approximately $80 \%$ of high school and college athletes believed that specializing to play one sport helped athletes play at a higher level (Buckley et al., 2017).

Correlation existed between Buckley et al's findings and the results of the current research; every student-athlete interviewed declined in the number of sports played throughout their lifetime. Of the 37 participants, $89.2 \%(n=33)$ competed in only one high school sport, though all had played at least one other sport in previous years. The four student-athletes competing in two sports in high school all ran cross-country, with varying additional sports. The average number of sports each participant played in their lifetime was 3.7, but dropped to an average of 1.1 sports still actively played in high 
school. The student athletes from the current research were acutely aware of the low likelihood of playing their respective sport in college, and the range of reactions to that fact suggests it is a topic worth pursuing further research on.

\section{CONCLUSION}

The current research utilized a case study structure to understand the factors that most impacted motivations of female high school student athletes to continue participating in athletics throughout high school. Study participants were high school sophomores, juniors and seniors at the time of the interview that were actively competing in a sport, and who had competed in the same sport the previous year. This sample population was specifically selected to ensure that the experiences studied were those of students who were motivated to continue competing in high school athletics beyond their first year in high school. Student athletes were interviewed individually using a semi-structured interview format, which allowed each interview to explore a wide variety of factors specific to each participant. The results of the current research may better inform junior high and high school athletic coaches and administrators and allow them to design more effective athletic programs for female adolescents, thus increasing overall participation and retention of female student-athletes.

Important findings from the current research were a positive impact between strong team cohesion and motivation, a desire to take values and lessons learned in sport and apply them to life beyond sport, and a notable rejection of distinctly extrinsic factors of motivation. Student athletes frequently referenced that positive experiences with teammates and coaches, regardless of the team's success in competition, were likely to motivate them to return the next year. Most participants in the strongly internalized values learned in sport and continued to seek out opportunities through athletics to further develop their life skills. Specific values discussed included self-discipline, perseverance, determination, and correcting mistakes.

An unexpected trend that was revealed was an acute awareness of the prospects of competing in athletics beyond high school. Although never asked or suggested by the interviewer, $43.2 \%$ of participants mentioned the likelihood of competing in college as an impacting factor on their high school motivation. This awareness may be attributed to parental or peer pressure, heightened media coverage of high school and college athletics, or the significant visibility of the recruiting process through social and traditional media outlets, but to date there is limited research on the pressures high school student athletes face when considering competing in sport in college.

Study participants were also asked to discuss the least impactful factors on their motivation. The most frequently discussed statements as not impactful were those classified as external regulation, introjected regulation, and amotivation. Respectively, those categories reflect impacts by external influences, absorbing values from the environment, but not identifying them as part of the self-being, and lack of motivation (Kromerova \& Šukys, 2016). These findings align with the major theme discussed earlier that student athletes are largely motivated by intrinsic factors, but not often impacted by the desires of their parents, coaches, or peers.

The current research was not without limitations, primarily due to the available participant population. Due to accessibility, time and scheduling restraints with the student athletes' schedules, and the additional criteria to qualify for the study, the available population and eventual sample was less than desired. Additionally, the notable decline in physical activity participation is predominantly among female athletes, but understanding differences between male and female motivation could allow for additional insight as to why that decline exists so much more among females. With additional time and resources, the current research could have been strengthened by also interviewing male student athletes who met the same criteria.

The second limitation again relates to population availability, as the only student athletes interviewed were those who were actively competing. Former student athletes, who for whatever reason had chosen not to continue participating, were not involved in the study. Their perspectives could have provided valuable insight, as they would have been able to share what drove them to stop playing, what motivated them until the point they decided to quit, what could have convinced them to continue, or influencers on their decision. The population of former student athletes was not logistically feasible to find, as the current research communicated through coaches and athletic directors to find student athletes to participate in the study. Collaborating with each campus' athletic 
director and team coaches allowed for specifically scheduled access to actively competing student athletes, but did not facilitate interviews with those who had quit.

Future research related to student athlete sport participation should address the aforementioned populations, in order to put together a more complete sense of how different population groups are impacted by differing factors of motivation. The population studied in the current research came from two public, co-ed high schools in the Far West region, but additional research exploring other regions, socioeconomic status, and other backgrounds would also be valuable.

Beyond exploring additional population samples, the current research's findings on high school student athletes' concern for their future athletic prospects suggests a necessity for further research on the subject. The current research showed that students as young as sophomores expressed concern about their playing careers beyond high school, and yet limited research exists on how the pressure of continuing to compete in sports in college impacts student athletes still in high school. Whether it carries a positive or negative impact on motivation, the current research suggests it is, at minimum, something to be aware of, and in some instances can be a major stressor for high school student athletes. With the visibility of the National Collegiate Athletic Association and its student athletes becoming greater, discussions of stress management, and mental health among athletes is becoming more public (Lentz, Kerins, \& Smith, 2018) and the value of an athletic scholarship to college increasing, the correlation between pressure to compete in college and its impacts on high school student athletes will become a critical element to better understand.

There are valuable implications for multiple groups that could affect female adolescent sport participants in the future, including high school athletic directors, high school coaches, middle school sport associations, and parents of high school student athletes. Understanding the high value placed on team cohesion, life skills, values, and intrinsic motivators will allow athletic directors to develop programs and hire staff members that will better cater towards the goals and needs of female athletes. Encouraging other female students to participate in athletics can be better guided by these results, which in turn will begin to counter the declining trend of female high school sport participation.

For coaches, taking time to develop team chemistry and cohesion, elements not always included in practice, will foster an environment that encourages positive relationships among teammates. Taking time to cultivate positive team cohesion will in turn increase the likelihood that athletes will return in subsequent years. Appreciating team cohesion as highly as physical fitness, skill development, and tactical development will allow athletic programs to develop more consistent depth as student athletes become more likely to return each year. In addition, spending time teaching the values of sport that can have positive impacts on the student athletes' social life may contribute to an increase in overall interest level in competing in high school athletics.

Parents and guardians of high school student athletes are not likely to have a stake in developing programs or allocating practice time, but understanding what is likely to motivate their child can allow for more effective dialogue. Knowing that female student athletes are not heavily influenced by prestige, by being forced to join a sport, or by other external factors, will give parents, guardians, and coaches the opportunity to have more constructive conversations related to sport participation. Furthermore, the current research's findings show that high school student athletes participate in fewer sports than they did in younger years, combined with the existing research on the risks and detrimental impacts of early sport specialization, suggests to parents and guardians that encouraging their daughters to explore participation in multiple sports can have long-term benefits for their life.

\section{REFERENCES}

[1] Aaron, D. J., Storti, K. L., Robertson, R. J., Kriska, A. M., \& Laporte, R. E. (2002). Longitudinal study of the number and choice of leisure time physical activities from mid to late adolescence. Archives of Pediatrics \& Adolescent Medicine, 156, 1075-1080.

[2] Alderman, R. B., \& Wood, N. L. (1976). An analysis of inventive motivation in young Canadian athletes. Canadian Journal of Applied Sport Sciences, 1, 169-176.

[3] Allen, J. B. (2003). Social motivation in youth sport. Journal of Sport and Exercise Psychology, 25(4), 551-567.

[4] Allison, K. R., \& Adlaf, E. M. (1997). Age and sex differences in physical inactivity among Ontario teenagers. Canadian Journal of Public Health, 88(3), 177-180. 
[5] Berger, I. E., O’Reilly, N., Parent, M. M., Séguin, B., \& Hernandez, T. (2008). Determinants of sport participation among Canadian adolescents. Sport Management Review, 11, 277-307.

[6] Black, A., \& Deci, E. (2000). The effects of instructors' autonomy support and students' autonomous motivation on learning organic chemistry: A self-determination theory perspective. Science Education. 84(6), 740-756.

[7] Braun, V., \& Clarke, V. (2006). Using thematic analysis in psychology. Qualitative Research in Psychology. 3(2). 77-101.

[8] Brodkin, P., \& Weiss, M. R. (1990). Developmental differences in motivation for participating in competitive swimming. Journal of Sport \& Exercise Psychology, 12, 248-263.

[9] Buckley, P. S., Bishop, M., Kane, P., Ciccotti, M. C., Selverian, S., Exume, D.,...Ciccotti, M. G. (2017). Early single-sport specialization: A survey of 3090 high school, collegiate, and professional athletes. Orthopaedic Journal of Sports Medicine, 5(7).

[10] Casper, J. M., Bocarro, J. N., Kanters, M. A., \& Floyd, M. F. (2011). “Just let me play!”-Understanding constraints that limit adolescent sport participation. Journal of Physical Activity and Health, 8(S1), S32S39.

[11] Caspersen, C. J., Pereira, M. A., \& Curran, K. M. (2000). Changes in physical activity patterns in the United States, by sex and cross-sectional age. Medicine and Science in Sports and Exercise, 32(9), 16011609.

[12] Danioni, F., Barni, D., \& Rosnati, R. (2017). Transmitting sport values: The importance of parental involvement in children's sport activity. Europe's Journal of Psychology, 13(1), 75-92.

[13] Dwyer, J. J., Allison, K. R., Goldenberg, E. R., Fein, A. J., Yoshida, K. K., \& Boutilier, M. A. (2006). Adolescent girls' perceived barriers to participation in physical activity. Adolescence, 41(161), 76-89.

[14] Escartí, A. \& Gutiérrez, M, (2001). Influence of the motivational climate in physical education on the intention to practice physical activity or sport. European Journal of Sport Science, 1(4), 1-12.

[15] Finne, E., Bucksch, J., Lampert, T., \& Kolip, P. (2011). Age, puberty, body dissatisfaction, and physical activity decline in adolescents. Results of the German health interview and examination survey (KiGGS). International Journal of Behavioral Nutrition and Physical Activity, 8(1), 119-132.

[16] Gagné, M., \& Deci, E. (2005). Self-determination theory and work motivation. Journal of Organizational Behavior, 26(4), 331-362.

[17] Garcia, A. W., Broda, M. A., Frenn, M., Coviak, C., Pender, N. J., \& Ronis, D. L. (1995). Gender and developmental differences in exercise beliefs among youth and prediction of their exercise behavior. Journal of School Health, 65(6), 213-219.

[18] Garcia-Mas, A., Palou, P., Gili, M., Ponseti, X., Borras, P. A., Vidal, J.,..Sousa, C. (2010). Commitment, enjoyment and motivation in young soccer competitive players. The Spanish Journal of Psychology, 13(2), 609-616.

[19] Graham, S. (1997). Using attribution theory to understand social and academic motivation in African American youth. Educational Psychologist, 32(1), 21-34.

[20] Harry, B., Sturges, K. M., \& Klingner, J. K. (2005). Mapping the process: An exemplar of process and challenge in grounded theory analysis. Educational Researcher, 34(2), 3-13.

[21] Jayanthi, N., Pinkham, C., Dugas, L., Patrick, B., \& Labella, C. (2013). Sports specialization in young athletes. Sports Health: A Multidisciplinary Approach,5(3), 251-257.

[22] Jones, I. (2015). Research methods for sports studies (3rd ed.). London: Routledge.

[23] Kin-Isler, A., Asci, F. H., Altintas, A., \& Guven-Karaban, B. (2009). Physical activity levels and patterns of 11-14 year-old Turkish adolescents, Adolescence, 44(176), 1005-1015.

[24] Kremer-Sadlik, T., \& Kim, J. L. (2007). Lessons from sports: children's socialization to values through family interaction during sports activities. Discourse \& Society, 18(1), 35-52.

[25] Kromerova, E., \& Šukys, S. (2016). Adolescent involvement in sports activities and internalisation of moral values. Baltic Journal of Sport and Health Sciences, 1(100), 22-30.

[26] Kumar, R. (2017). Impact of physical education and sports in promoting social values among youth. International Journal of Indian Psychology, 4(2), 84-87.

[27] Lentz, B., Kerins, M. L., \& Smith, J. (2018). Stress, mental health and the coach-athlete relationship: A literature review. Applied research in coaching athletics annual, 33, 1-25.

[28] Lonsdale, C., Hodge, K., \& Rose, E. A. (2008). The behavioral regulation in sport questionnaire (BRSQ): Instrument development and initial validity evidence. Journal of Sport and Exercise Psychology, 30(3), 323-355.

[29] Mallett, C., Kawabata, M., Newcombe, P., Otero-Forero, A., \& Jackson, S. (2007). Sport motivation scale- 
6 (SMS-6): A revised six-factor sport motivation scale. Psychology of Sport and Exercise, 8(5), 600-614.

[30] MSLGROUP Research. (2016). Always confidence \& puberty wave IV study.

[31] Niemiec, C., \& Ryan, R. (2009). Autonomy, competence, and relatedness in the classroom: Applying selfdetermination theory to educational practice. Theory and Research in Education. 7(2), 133-144.

[32] Orhan, Ö. (2015). The relationship between physical activity level, body mass index, and body fat percentage in urban and rural elementary school students. Educational Research and Reviews, 10(1), 6974.

[33] Pacheco, L. A., Mas, F. S., Olivarez, A., \& Avila, M. (2012). Motivational factors related to female participation in collegiate sports. Journal of Human Sport and Exercise, 7(4), 783-793.

[34] Paradis, K., \& Loughead, T. M. (2010). Examining the mediating role of cohesion between athlete leadership and athlete satisfaction in youth sport. International Journal of Sport Psychology, 41(1).

[35] Pelletier, L. G., Tuson, K. M., Fortier, M. S., Vallerand, R. J., Briére, N. M., \& Blais, M. R. (1995). Toward a new measure of intrinsic motivation, extrinsic motivation, and amotivation in sports: The sport motivation scale (SMS). Journal of Sport and Exercise Psychology, 17(1), 35-53.

[36] Ryan, R., \& Deci, E. (2000). Self-determination theory and the facilitation of intrinsic motivation, social development, and well-being. American Psychologist, 55(1), 68-78.

[37] Ryan, R., Rigby, C. S., \& Przybylski, A. (2006). The motivational pull of video games: A selfdetermination theory approach. Motivation and Emotion. 30(4), 344-360.

[38] Sabo, D., \& Veliz, P. (2008). Go out and play: Youth sports in America. East Meadow, NY: Women's Sports Foundation.

[39] Sallis, J. F., Prochaska, J. J., \& Taylor, W. C. (2000). A review of correlates of physical activity of children and adolescents. Medicine and Science in Sports and Exercise, 32(5), 963-975.

[40] Stubbe, J. H., Boomsma, D. I., \& de Geus, E. J. C. (2005). Sports participation during adolescence: A shift from environment to genetic factors. Medicine and Science in Sports and Exercise, 37(4), 563-570.

[41] Stupuris, T., Šukys, S., \& Tilindienè, I. (2013). Relationship between adolescent athletes' values and behavior in sport and perceived coach's character development competency. Education. Physical Training. Sport., 91(4), 37-45.

[42] Telama, R., \& Yang, X. (2000). Decline of physical activity from youth to young adulthood in Finland. Medicine and Science in Sports and Exercise, 32(9), 1617-1622.

[43] Vincer, D., \& Loughead, T. M. (2010). Relationship among athlete leadership behaviors and cohesion in team sports. Sport Psychologist, 24 (4), 448-467.

[44] Weinberg, R., Tenenbaum, G., McKenzie, A., Jackson, S., Anshel, M., Grove, R., \& Fogarty, G. (2000). Motivation for youth participation in sport and physical activity: Relationships to culture, self-reported activity levels, and gender. International Journal of Sport Psychology, 31(3), 321-346.

[45] Whitehead, J., \& Corbin, C. (1997). Self-esteem in children and youth: The role of sport and physical education. In K. Fox (ed.), The Physical Self (175-203). Champaign, IL: Human Kinetics Publishers.

[46] Whitehead, S., \& Biddle, S. (2008). Adolescent girls' perceptions of physical activity: A focus group study. European Physical Education Review, 14(2), 243-262.

[47] Yin, R. K. (2009). Case study research: Design and methods. Los Angeles: SAGE Publications.

Citation: Sinead Nelson, Jimmy Smith. "Female Adolescent Physical Activity Motivation: A Qualitative Implementation of the BRSQ " International Journal of Sports and Physical Education (IJSPE), vol 5, no.2, 2019, pp. 1-12. doi: http://dx.doi.org/10.20431/2454-6380.0502001.

Copyright: (C) 2019 Authors. This is an open-access article distributed under the terms of the Creative Commons Attribution License, which permits unrestricted use, distribution, and reproduction in any medium, provided the original author and source are credited. 